\title{
OS MODELOS DE ESTADO E AS CARACTERÍSTICAS DA JURISDIÇÃO
}

\begin{abstract}
Ana Luísa Zago de Moraes ${ }^{1}$
Resumo: O Estado Moderno, diferentemente das formas pré-modernas de organização, é caracterizado pela dominação burocrática. Apresentou-se inicialmente como Estado Absoluto, em face do qual se opôs o Estado Liberal e, posteriormente o Estado Social. O Estado de Direito, produto de meados do século XIX, erigiu-se tendo como conteúdo tanto o social como o liberal, porém sua forma mais atual é a do Estado Democrático de Direito, um modelo ideal que exige a satisfação de direitos e garantias fundamentais tanto individuais como coletivas. A organização judiciária, desde a institucionalização dos Estados absolutos, passou por várias etapas, dentre elas a de sua própria estruturação mediante a influência dos ideais surgidos nas universidades entre os séculos XII XIII até a sua crise derivada da própria relativização do conceito de soberania e o surgimento dos Tribunais internacionais. Tem, como modelos ideais de juízes, "Júpiter", o legalista baseado na pirâmide kelseneana, "Hércules", o assistencialista, que utiliza a pirâmide invertida, e "Hermes", comprometido com as "regras do jogo", os direitos e garantias fundamentais e as responsabilidades de todos perante os problemas mundiais.
\end{abstract}

\section{Palavras-chave: Modelos de Estado - Sistemas de Direito - Jurisdição}

Abstract: Being distinct from other forms of premodern organization, The Modern State is characterized by bureaucratic domination. It presented itself initially as an Absolute State, in which it opposed to the Liberal State and, posteriorly, to the Social State. The Law State, a product from around the $19^{\text {th }}$ century, was built up having the social as well as the liberal as content, however, its more present form is the Democratic State of Law, an ideal model which demands the satisfaction of rights and fundamental guarantees both individually and collectively. The judiciary organization, since the institutionalization of absolute States, has been through various stages, amongst them its own structuring in light of the influence of ideals that emerged in universities between the $12^{\text {th }}$ and $18^{\text {th }}$ centuries up to its crisis, derived from the own relativizing of the sovereignty concept and the appearance of international Courts of Law. It takes, as ideal role models for judges, "Jupiter", the legalist based on Kelsen's pyramid, "Hercules", the assistentialist that uses the inverted pyramid, and "Hermes", engaged to the "rules of the game", the rights and fundamental guarantees and the responsibilities of all before world problems.

Keywords: State Models - Law Sistems - Jurisdiction

\section{INTRODUÇÃO}

A Ciência Política é a disciplina que, mediante um processo de compreensão transdisciplinar, possibilita interpretar a complexidade que envolve o Estado, o poder, a política, a democracia e o direito. Assim, pretende estudar o Estado, sua estrutura e seu funcionamento, bem como sua relação com o sistema jurídico, uma vez que o Estado é lugar privilegiado de emanação da normatividade (STRECK; MORAIS, 2004, p. 18-19).

\footnotetext{
${ }^{1}$ Graduada em Direito pela UFSM. Mestranda em Ciências Criminais pela PUC-RS.
}

(C) 2008. Departamento de Direito da UFSM. Todos os direitos reservados. 
Daí porque a opção para o estudo da temática dos modelos de Estado e das características da jurisdição à luz desta ciência.

Lênio Streck e José Luis Bolzan de Morais denominam o Estado Antigo (Oriental ou Teocrático), o Estado Grego, o Estado Romano e o Estado Medieval de formas estatais pré-modernas, em que não havia clara distinção entre as relações privadas e as públicas, ou seja, a dicotomia entre Estado e sociedade civil, tampouco as características fundamentais do Estado Moderno: território e povo (elementos materiais) e governo, poder autoridade e soberania (elementos formais). Da mesma forma, o tipo de dominação diferencia-se entre ambos tipos estatais, sendo que na moderna passa a ser legal-racional, ao passo que na anterior era baseada no carisma do soberano (STRECK; MORAIS, 2004, p. 26).

Max Weber dicotomiza as organizações estatais em duas grandes categorias: a baseada na propriedade, ou seja, a associação feudalmente estruturada, e a com base na separação dos meios de administração do quadro administrativo. Esta é forma do Estado Moderno, que é do Estado burocrático, assim conceituada (WEBER, 1964, p. 17):

uma associação de domínio com carácter institucional que tratou, com êxito, de monopolizar, dentro de um território, a violência física e legítima como meio de domínio e que, para esse fim, reuniu todos os meios materiais nas mãos do seu dirigente e expropriou todos os funcionários feudais que anteriormente deles dispunham por direito próprio, substituindo-os pelas suas próprias hierarquias supremas.

O presente trabalho objetiva a análise das formas estatais modernas e das características da jurisdição delas decorrentes, sem deixar de reconhecer a importância, entretanto, das formas anteriores. Será dividido, pois, entre os modelos de Estado modernos e os respectivos tipos de jurisdição características.

\section{Os modelos de Estado Moderno}

A primeira expressão do Estado Moderno foi alicerçada na concentração de todos os poderes nas mãos dos monarcas, o que vai originar as chamadas monarquias absolutistas, em que o Estado era personificado na figura do rei, exemplificada pela frase "L'État c'est moi”, de Luiz XIV, o Rei Sol, que reflete o apogeu do absolutismo na França (BAUMER, 1977, p. 177). Com isso, as monarquias absolutistas se apropriaram dos

(C) 2008. Departamento de Direito da UFSM. Todos os direitos reservados. 
Estados como sua propriedade, o que era alicerçado da idéia de que o poder estatal tinha origem divina, e o rei era o representante de Deus sobre a terra, sem qualquer limitação de poder. Sua grande contribuição foi assegurar a unidade territorial dos reinos, sustentando um dos elementos fundamentais da do Estado moderno: o território (STRECK; MORAIS, 2004, p. 45).

Hobbes, sustentando que o contrato social é um pacto em favor de um terceiro, o Leviatã, o "deus mortal", com o objetivo de preservar suas vidas, forneceu uma base teórica de legitimação a esta forma de Estado. Por outro lado, Locke altera substancialmente o conteúdo do contrato, referindo que a convenção é limitada pelos direitos naturais, e que o "pacto de consentimento" serve para preservar os direitos já existentes no estado de natureza, já esboçando um quadro primário do individualismo liberal, que diferencia o governo civil da religião e inicia o protesto contra o absolutismo na Inglaterra.

Na França os protestos contra o absolutismo surgiram também no século XVII e foi se tornando mais significativo, principalmente pela influência do terceiro contratualista, Rousseau, e do descontentamento, por parte da burguesia, ao obter somente o poder econômico e manter-se a afastada do político. Tal culminou, em 1789, na Revolução Francesa, marco inaugural de uma nova fase do Estado moderno (STRECK; MORAIS, 2004, p. 49).

O liberalismo, nesse contexto, foi uma doutrina construída contra o absolutismo, e, portanto, intencionado à limitação do poder, baseada no crescimento do individualismo, que se consolidou no século XIX (DUMONT, 1985). Norberto Bobbio o conceitua como "uma determinada concepção de Estado, na qual o Estado tem poderes e funções limitadas, e como tal se contrapõe tanto ao Estado absoluto quanto ao Estado que hoje chamamos de social" (BOBBIO, 1988, p. 17).

O núcleo político do liberalismo é caracterizado pela teoria do consentimento, que é fonte da autoridade política e dos poderes do Estado, pela representação, já que os parlamentares seriam eleitos pelo povo, pelo constitucionalismo e pela soberania popular (ideal rousseauniano da participação popular). Além deste núcleo, existe também o moral e o econômico - capitalismo, cujos pilares são a propriedade privada e a economia de mercado livre de controles estatais (STRECK; MORAIS, 2004, p. 55).

(C) 2008. Departamento de Direito da UFSM. Todos os direitos reservados. 
A passagem da fórmula liberal do Estado Mínimo para o Estado Social, a partir de meados do século XIX, caracterizou-se pela atuação positiva do Estado mediante prestações públicas a serem asseguradas ao cidadão como direitos peculiares à cidadania. A justiça social surgiu como novo ideal surgido da necessidade de apoiar os indivíduos de uma outra forma quando sua autoconfiança e sua iniciativa não podiam mais lhes dar proteção, ou quando o mercado não podia mais lhe satisfazer as necessidades básicas. As guerras mundiais foram um dos fatores que contribuíram para esse modelo, bem como a crise econômica de 1929 e a Depressão.

O Welfare State consolidou-se, pois, como garantidor de "tipos mínimos de renda, alimentação, saúde, habitação, educação, assegurados a todos os cidadãos, não como caridade, mas como direito político" (BOBBIO apud STRECK, 2004, p. 71).

O Estado de Direito, por seu turno, emerge como construção teórica própria da segunda metade do século XIX, na Alemanha, tendo sido logo incorporada pela França. Surge como o Estado que, nas suas relações com os indivíduos, se submete a regime de direito, motivo pelo qual a atividade estatal apenas pode desenvolver-se utilizando um instrumental regulado pela ordem jurídica. Os indivíduos, por sua vez, têm a seu dispor mecanismos jurídicos aptos em face de ações abusivas do Estado. Pode apresentar-se, quanto ao seu conteúdo, como liberal, social e, por fim, como democrático.

Luigi Ferrajoli designa o Estado de Direito não simplesmente um “estado legal” ou "regulado pelas leis", mas um modelo de Estado nascido com as modernas Constituições e caracterizado:

a) no plano formal, pelo princípio da legalidade, por força do qual todo poder público - legislativo, judiciário, e administrativo - está subordinado às leis gerais e abstratas que lhes disciplinam as formas de exercício e cuja observância é submetida a controle de legitimidade por parte dos juizes delas separados e independentes; b) no plano substancial da funcionalização de todos os poderes do Estado à garantia dos direitos fundamentais dos cidadãos, por todos os meios de incorporação limitadora em sua Constituição dos deveres públicos correspondentes. (FERRAJOLI, 2006, p. 805)

Portanto, não existem, no Estado de direito, poderes desregulados e atos de poder sem controle, já que todos os poderes são assim limitados por deveres jurídicos, relativos não somente à forma, mas também aos conteúdos de seu exercício, cuja violação é causa de invalidez judicial dos atos e, ao menos em teoria, de responsabilidade de seus autores. 
O Estado Democrático de Direito surgiu, no século XX, com a tentativa de conjugar o ideal democrático ao Estado de Direito, e é regido pelos princípios da Constitucionalidade, da Organização Democrática da Sociedade, do Sistema direitos fundamentais individuais e coletivos, da Justiça Social, da Igualdade, da Divisão de Poderes ou de Funções, da Legalidade e da Segurança e Certeza Jurídicas. A antítese da democracia é o totalitarismo surgido no século XX e caracterizado pela penetração no corpo social com a destruição da distinção do aparelho político e da sociedade (ARENDT, 1989).

\section{O (re)surgimento do Direito no Estado moderno e sua repercussão nas características da jurisdição}

O renascimento que se produz nos séculos XII e XIII no Ocidente Europeu manifesta-se em todos os planos, e é tão revolucionário como o que se produziu no século XVIII. Um dos seus aspectos mais importantes é o jurídico. A própria Igreja distingue mais nitidamente a sociedade religiosa dos fiéis da sociedade laica e elabora, nessa época, um direito privado canônico (DAVID, 2002, p. 39).

Nesse período, o direito romano voltou a ser estudado nas universidades com a finalidade de superar os direitos locais, baseados em costumes já ultrapassados. Contra esse direito romano, sobre o qual o próprio direito canônico se fundara, elevara-se a crítica de que poderia afastar-se da "lei divina", por ser um direito pagão. Entretanto, após o apoio de São Tomás de Aquino, no início do século XIII, eliminou-se tal objeção.

Nessa época surgiram as "escolas", dentre elas a escola dos glosadores, que procurou reencontrar e explicar o sentido originário das leis romanas. Posteriormente, os séculos XIV e XV, os pós-glosadores ensinam o usus modernus Pandectarum, um direito romano profundamente deformado, especialmente sob a influência do direito canônico.

Após, uma nova escola, preocupada com a racionalidade, dita o direito natural, que triunfa nas universidades nos séculos XVII e XVIII. Segundo René David, este "abandona o método escolástico, eleva a um alto grau a sistematização do direito, que ela concebe de modo axiomático, eminentemente lógico, à imitação das ciências" (GAUER, 2006). Afastase, pois, da idéia de uma ordem natural exigida por Deus, e pretende construir toda ordem

(C) 2008. Departamento de Direito da UFSM. Todos os direitos reservados. 
social sobre a consideração do homem, exaltando os "direitos naturais" do indivíduo, motivo pelo qual a idéia de direito subjetivo passa a dominar o pensamento jurídico (DAVID, 2002, p. 46-47).

Surge, da idéia de universalismo e do repúdio aos costumes locais, o apelo à legislação, bem como a dicotomia entre direito privado e direito público. Não abandonou, no entanto, o direito romano, porém propôs as novas bases referidas, complementando-as com as Constituições, novas práticas administrativas e o direito criminal.

Essa sistematização, que surgiu nas universidades nos séculos XII e XIII, era intencionada também a convencer as populações, os dirigentes e, sobretudo, os juízes que, nessa época, não só aplicavam, mas também determinavam o direito aplicável. Foi então que uma decisão do Concílio de Latrão, em 1215, proibiu os clérigos de participarem em processos nos quais se recorresse aos ordálios ou aos juízos de Deus.

Assim, passou-se a reconhecer a impossibilidade de que os processos fossem resolvidos pelo apelo ao sobrenatural, mediante o uso de provas irracionais. Logo, a consequiência prática foi a adoção de um novo processo, racional, que terá como modelo o direito canônico, em substituição ao sistema carolíngio, na qual o juiz dirigia o processo, enquanto os almotacés afirmavam qual era o costume e pronunciavam a decisão (DAVID, 2002, p. 49).

Esse novo modelo de justiça, que surge nos séculos XII a XVI, é caracterizado pelo exercício exclusivo por juristas letrados, formados nas universidades, na escola do direito romano. Exemplo disso é o surgimento, nesse último século, de um grande Tribunal Real, na França, o Parlamento de Paris, que se constitui como um tribunal soberano, participante do governo do reino, que foge do uso dos costumes locais para apoiar-se num direito mais geral, com uso predominante do direito romano. Posteriormente, surgem na França os tribunais das províncias. Ainda, nos séculos XVI e XVII, esses tribunais, além do direito romano, da equidade, e de outras fontes, passam a fazer uso das "decisões regulamentares", ou seja, dos precedentes das próprias cortes. Outra tentativa foi na Itália, no século XII, com os juízes itinerantes, para que, propositadamente, não se baseassem nos usos e costumes locais (DAVID, 2002, p. 61-62).

Nesse período de racionalização da organização judiciária, o papel da legislação era secundário. $\mathrm{O}$ soberano apenas organizava os tribunais de justiça e regulava o processo, 
porém não o direito por eles utilizado. Desempenhavam, ainda, um papel de ordenação do direito criminal, porém no direito privado seu papel era ínfimo.

A unificação das legislações, assim, iniciou timidamente mediante compilações privadas ou oficiais a partir do século XIII até o século XVIII. É a partir deste último século, com a influência da escola do direito natural, que inicia a codificação, o que posteriormente passou a gerar a crise relativa à necessidade de fazer progredir a ciência jurídica e aperfeiçoar o direito.

Atualmente, consolidadas as justiças nacionais, poderes do Estado, bem como os códigos e Constituições, surgem novas tendências, tais como o desenvolvimento do direito comparado e a multiplicação das convenções internacionais, o que será analisado ao tratarse da jurisdição contemporânea.

\section{As crises do Estado na contemporaneidade e a repercussão na jurisdição estatal}

A idéia de soberania surgiu no final do século XV e início do século XVI, como categoria filosófico-jurídica de construção jusnaturalista, ou seja, é um resquício prémoderno que está na origem da modernidade jurídica. Caracteriza-se, historicamente, por um poder pelo qual se tem a capacidade de "definir e decidir acerca do conteúdo e aplicação das normas, impondo-as coercitivamente dentro de determinado espaço geográfico, bem como de fazer frente a eventuais injunções externas". É, assim, tradicionalmente tida como uma, indivisível, inalienável e imprescritível (STRECK; MORAIS, 2004, p. 131).

Ocorre que, de lá para cá, o tema tem sofrido transformações significativas para adaptar-se às novas circunstâncias históricas impostas pelas mutações por que passaram os Estados, bem como pelos novos laços que os unem nas relações interestatais (FERRAJOLI, 2002, p. 2). Ao lado do aprofundamento democrático das sociedades, o que ocasionou um descompasso entre a pretensão de um poder unitário e o caráter plural das mesmas, no plano internacional, observa-se o fenômeno relacionado ao atrelamento entre as idéias de soberania e cooperação jurídica, econômica e social.

As comunidades supranacionais - União Européia, NAFTA, MERCOSUL, entre outras -, traduzem-se em um regramento comum, inicialmente no que se refere ao

(C) 2008. Departamento de Direito da UFSM. Todos os direitos reservados. 
comércio internacional, tendo as tarifas alfandegárias como princípio, porém também avançam a uma jurisdição comum, com a criação de tribunais internacionais, o que se traduz em uma mudança na própria concepção tradicional de jurisdição. ${ }^{2}$ Também há as organizações de caráter universal, como a ONU, cujas decisões atingem, inclusive, os Estados não-membros, ao dispor, na Carta das Nações Unidas, em seu art. 2, parágrafo 6: "A organização fará com que os Estados que não são membros das Nações Unidas procedam de conformidade com estes princípios na medida necessária à manutenção da paz e da segurança internacionais" (RESEK, 2005, p. 253).

Quanto à jurisdição internacional, no século XX foi muito utilizada a arbitragem, que é um mecanismo jurisdicional não judiciário, porém que conduz a uma decisão obrigatória àqueles que firmaram o compromisso arbitral. Ao contrário disso, a jurisdição judiciária é um fenômeno recente na cena internacional, tendo sido o primeiro órgão a Corte de Justiça Centro-Americana, instituído em 1907, com duração de dez anos, aberta, inclusive, aos particulares. A Corte de Haia, fundada em 1920, por seu turno, é mais importante dentre os tribunais internacionais, foi o primeiro dotado de jurisdição universal, tendo sido fechado em 1939 e reaberto em 1945, com a denominação de Corte Internacional de Justiça (RESEK, 2005, p. 356-357).

\section{A jurisdição contemporânea: uma abordagem acerca dos modelos de juiz}

O modelo jurídico clássico, que continua sendo ensinado nas faculdades de direito, é o modelo de Direito codificado. Este surgiu, consoante já explicitado, pelo ideal das academias de unificar e racionalizar o direito vigente, em detrimento dos direitos costumeiros anteriormente aplicados. Tal direito codificado, reduzido à simplicidade de uma obra única, se articula de forma hierárquica e piramidal, como proposto pelos positivistas, dentre eles Hans Kelsen, que preleciona ser o sistema jurídico uma pirâmide ou hierarquia de normas que são superpostas ou subordinadas umas às outras, superiores ou inferiores. No topo da pirâmide encontra-se a norma fundamental, que habilita à autoridade

\footnotetext{
${ }^{2}$ Não se pode olvidar, ainda, a importância das ONG's e de organizações internacionais destinadas à proteção dos direitos humanos.
}

(C) 2008. Departamento de Direito da UFSM. Todos os direitos reservados. 
suprema criar o direito válido, uma ficção necessária para a validação positivista dos ordenamentos jurídicos em vigor (KELSEN, 2002).

François Ost refere que este é o modelo que atende às exigências do Estado Liberal ou do Estado de Direito do século XIX, o qual denomina o modelo de "Júpiter", atido à pirâmide de normas. Refere ser caracterizado pelo monismo jurídico, pelo monismo político ou soberania estatal - supõe o resultado de um processo de identificação nacional e de centralização administrativa que culmina na figura do soberano -, pela racionalidade dedutiva e linear, apta a garantir coerência lógica e harmonia ideológica ao sistema, e, derradeiramente, pela concepção de tempo orientado a um futuro controlado (OST, 1993, p. 175).

Em contraposição à dureza do liberalismo econômico que se desenvolveu ao amparo do juridicismo formal, a "miopia legalista do século XIX", surge o que Ost denomina a figura de "Hércules", o juiz-assistencialista típico do Estado Social do século XX. A contrário de "Júpiter", que era um homem da lei, passa ser um engenheiro social, relativizando o mito da supremacia do legislador, encontrando sua maior expressão nos Estados Unidos, com as correntes do realismo e da sociological jurisprudence (OST, 1993, p. 177).

O Direito passa a ser visto mediante a fórmula da pirâmide invertida, ou seja, com a supremacia do fato concreto perante as normas abstratas. O direito se reduz ao fato, à indiscutível materialidade das decisões. Assim, a jurisprudência torna-se capaz de adaptar o texto da lei às necessidades do momento.

A ambos estes pólos opostos, se contrapõe "Hermes", substituindo o monismo pelo pluralismo, o absolutismo binário (proibição-permissão, validade-invalidade), pelo relativismo e gradualismo, a linearidade hierárquica pelo recursividade fecunda, a clausura e o determinismo do discurso pelo discurso jurídico hermenêutico. Tal é herança das crises do Direito liberal gerado pelo Estado de Direito e do Direito social produzido pelo Estado assistencial, e do surgimento de um direito pós-moderno, cujos contornos não se delineiam nitidamente, devido ao grau de complexidade da situação presente (OST, 1993, p. 183).

O primeiro indício desse grau de complexidade é a multiplicidade atores processuais, da forma desses atores (sindicados, entre outros), da multiplicação dos níveis de poder - desde as autoridades locais até a transferência de soberania aos ordenamentos

(C) 2008. Departamento de Direito da UFSM. Todos os direitos reservados. 
jurídicos supranacionais europeus. Por esse motivo, proibição e permissão não são mais suficientes, surgindo os planos, as recomendações, as declarações governamentais, os pactos políticos. Assim, do lado da despenalização e da desjudicialização, encontram-se a fiscalização administrativa e os mecanismos de conciliação, mediação e arbitragem (OST, 1993, p. 186).

Assim, nos deparamos com um direito que, em certas ocasiões se apresenta como líquido, fluido, que lhe permite colocar-se nas situações mais diversas e ocupar suavemente todo o espaço disponível, suportando fortes compressões (ZAGREBELSKY, 1995). "Hermes" e a teoria lúdica que o simboliza, nesse contexto, se articula entre o direito e o fato, entre a ordem e a desordem, dando conta dessa racionalidade paradoxal.

Nesse aspecto, esta teoria lúdica admite o direito como um jogo com um número indefinido de jogadores e cujas regras e réplicas não estão inteiramente programadas, em que interpenetram jogos sociais e de linguagem. Nesse se cambiam a regra e o azar, a convenção e a intervenção, motivo pelo qual não se reduz ao respeito às regras, tampouco à indeterminação pura e simples.

Conclui Ost, portanto, que se "Júpiter" insiste na convenção e "Hércules" na invenção, "Hermes" respeita o caráter hermenêutico do juízo jurídico, que não se reduz nem à improvisação, nem à simples determinação de uma regra superior. Assim, a regra do jogo implica o respeito ao jogador e lhe garante a igualdade com os participantes mais experientes ou mais poderosos, para que, ao menos, possa fazer valer seu ponto de vista. Reconhece, ainda, os direitos de primeira, de segunda, e de terceira geração, porém atenta às normas intersubjetivamente válidas de responsabilidade universal, bem como à institucionalização da prudência, principalmente no que se refere aos riscos decorrentes de manipulações genéticas e nucleares, ou seja, de escala mundial, colocando em prática os projeto societários mais soberanos como único escudo contra o totalitarismo (OST, 1993, p. 192-194).

\section{CONSIDERAÇÕES FINAIS}

O Estado Moderno surgiu da necessidade de um poder soberano e de unificação territorial, em uma época caracterizada pela dominação feudal, ou seja, baseada na

(C) 2008. Departamento de Direito da UFSM. Todos os direitos reservados. 
propriedade e nas relações pessoais. Com isso, o Estado Absolutista foi responsável pela unificação territorial. Nessa época, no entanto, não havia uma Justiça estatal organizada, e o direito aplicado era o costumeiro, mediante um processo que utilizava instrumentos sobrenaturais e a prova tarifada. A transformação, no entanto, iniciou nas academias, mediante o resgate do Direito Romano, que influenciou primeiramente a França, no século XIV, a fundar o Tribunal Real, órgão oficial, uma justiça profissionalizada e técnica que deixa de utilizar o direito costumeiro.

A substituição do Estado Absolutista pelo Estado Liberal no século XVIII foi acompanhada, no âmbito jurídico, pela Codificação, que se traduz no imperativo da racionalização da legislação, unificação e coerência. Nessa época, os juízes não mais "fabricavam" as leis - selecionavam os costumes e outras fontes de direito - e o processo racional consolidou-se mediante provas não mais de origem divina e sim que comprovassem a "verdade" dos fatos. Os ideais de liberdade e igualdade também influenciaram a justiça, motivo pelo qual a previsibilidade dos códigos e a noção de que "a lei era igual para todos" satisfaziam os anseios burgueses de retirar os privilégios da nobreza.

Ocorre que, com o crescimento da população urbana, do "proletariado", com as grandes guerras e a crise econômica, o Estado Mínimo foi reputado insuficiente, sendo paulatinamente substituído pelo Estado Social. Nele, a posição da justiça era voltada à igualdade material, não mais formal, personificada no juiz "Hércules", em contraposição ao juiz "Hermes" do período anterior.

Atualmente, o modelo do Estado Democrático de Direito exige uma justiça que respeite as "regras do jogo", ou seja, direitos e garantias fundamentais, porém que também esteja consciente das responsabilidades de todos perante seus atos, bem como do papel atuante frente as problemas de repercussão mundial, como são os ambientais. Além disso, a própria concepção de jurisdição tem sido modificada pela relativização do conceito de soberania e a criação dos tribunais internacionais.

Por conseguinte, o presente texto, em que pese reconheça que a linearidade aqui traçada é nada mais do que a delimitação de tipos históricos ideais, que sequer estão aptos a retratar a realidade política e jurídica brasileira - que sequer chegou a consolidar-se como Estado Social, adotando o modelo do Estado Democrático de Direito pela Constituição

(C) 2008. Departamento de Direito da UFSM. Todos os direitos reservados. 
Federal de 1988 - tentou demonstrar a relação entre a evolução dos Estados, dos modelos de racionalidade construídos ao logo dos séculos, e as características da jurisdição. Ao mesmo tempo, nada mais fez do que trazer problemas, como a complexidade do século XXI e a repercussão no Direito e na Justiça, sem preocupar-se com soluções estereotipadas e imediatistas.

Entretanto, o objeto da pesquisa aqui apenas se esboça, trazendo o substrato teórico fundamental ao aprofundamento da pesquisa, à crítica e às soluções. Certo é, no entanto, que, como refere François Ost, "a tarefa de aplicar o Direito é uma obra hermenêutica, um trabalho sempre recomeçado" (OST, 1993, p. 194).

\section{REFERÊNCIAS BIBLOGRÁFICAS}

ARENDT, Hannah. O que é política? Trad. R. Guarany. Rio de Janeiro: Bertrand Brasil, 1998.

ARENDT, Hannah. Origens do Totalitarismo. Trad. Roberto Raposo. São Paulo: Editora Schwarcz Ltda., 1989.

BAUMER, Franklin Le Van. O pensamento europeu moderno - volume I - séculos XVII e XVIII. Rio de Janeiro: Edições 70, 1977.

BAUMER, Franklin Le Van. O pensamento europeu moderno - volume II - séculos XVII e XVIII. Rio de Janeiro: Edições 70, 1977.

BOBBIO, Norberto. Liberalismo e Democracia. São Paulo: Brasiliense, 1988.

BOBBIO, Norberto. Teoria do Ordenamento Jurídico. Trad. Maria Celeste Cordeiro Leite dos Santos. 10 Ed. Brasília: UNB, 1999. 
BOBBIO, Norberto. Teoria Geral da Política: A Filosofia Política e as Lições dos Clássicos. Org. Michelangelo Bovero. Trad. Daniela Versiani. Rio de Janeiro: Campus, 2000.

DAVID, René. Grandes Sistemas do Direito Contemporâneo. Trad. Hermínio. A. de Carvalho. São Paulo: Martins Fontes, 2002.

DUMONT, Louis. O individualismo - uma perspectiva antropológica da ideologia moderna. Rio de Janeiro: Rocco, 1985.

FERRAJOLI, Luigi. Direito e Razão. Trad. Ana Paula Zomer Sica et al.,2. Ed. São Paulo: Revista dos Tribunais, 2006.

FERRAJOLI, Luigi. A soberania no mundo moderno. Trad. Carlos Coccioli. Sao Paulo: Martins Fontes, 2002.

GAUER, Ruth. O Reino da Estupidez e o Reino da Razão. Rio de Janeiro: Lúmen Júris, 2006.

KELSEN, Hans. Teoria Pura do Direito. São Paulo: Martins Fontes, 2002.

OST, François. Júpiter, Hércules, Hermes: Tres modelos de juez. Trad. Isabel Lifante Vidal. DOXA - Cuadernos de Filosofia, número 14, 1993, p. 169-194. Disponível em http://www.cervantesvirtual.com/servlet/SirveObras/01360629872570728587891/cuaderno 14/doxa14_11.pdf. Acesso em 08.05.2006.

REZEK, Francisco. Direito Internacional Público. 10 Ed., São Paulo: Saraiva, 2005.

STRECK, Lenio Luiz; MORAIS, José Luis Bolzan. Ciência Política e Teoria Geral do Estado. Porto Alegre: Livraria do Advogado, 2004.

WEBER, Max. O político e o cientista. 3 Ed. Lisboa: Presença, 1964. 
ZAGREBELSKY. Gustavo. El derecho ductil: Ley, derechos, justicia. Editora Trottta: Madrid, 1995. 